\title{
A RAPID AND SENSITIVE METHOD FOR DETERMINATION OF CHLORINATED BY-PRODUCTS IN TAP WATER SAMPLES
}

\author{
GHAZALA YAQUB ${ }^{1 *}$, UNAIZA KHAN ${ }^{1}$; ZUBI SADIQ ${ }^{2}$, HASEEB AKRAM
}

${ }^{1}$ Department of Environmental Sciences, Kinnaird College for Women, Lahore-54000, Pakistan

${ }^{2}$ Department of Chemistry, Lahore College for Women University, Lahore-54000, Pakistan

\begin{abstract}
In this paper, an account for determination of chlorinated byproducts by High Performance Liquid Chromatography in various tap water samples is presented. The key objective of this study was to develop an analytical method for selectively and sensitively detecting the concentration of CBPs in addition to analyze selected parameters affecting CBP formation. Concentration of targeted compounds i.e. hydrazine sulfate, Dichloroacetic acid, Bromodichloromethane and chloroform were analyzed in tap water samples collected from a low socioeconomic area in a developing country. Hydrazine sulfate, Dichloroacetic acid and chloroform were detected in four water samples i.e. T4, T7, T9 and T10 while no samples contained Bromodichloromethane. Presence of these compounds in water is associated with cancer mortality and adverse reproductive outcomes.
\end{abstract} sulfate.

Key words: Bromodichloromethane; Chlorinated by-product; Chloroform; Dichloroacetic Acid; High Performance Liquid Chromatography; Hydrazine

\section{INTRODUCTION}

Water is required to sustain life but since long it has been a potential source of human illness ${ }^{1}$. Chlorination is considered to be the most efficient measure to improve the quality of water for the control of water born diseases in human beings ${ }^{2}$. Millions of people worldwide receive the quality disinfected drinking water every day from public water supply but the chemical disinfection has also raised a public health issue as chlorine occurs in disinfected water in the form of Hypochlorite and Hypochlorous acid which react with organic matter (Humic acid and Fulvic acid) to generate a class of disinfection chlorinated byproducts including Trihalomethane (THM), Halo-acetic acid (HAAs), Chlorophenols, Chloral hydrates and Halo-acetonitrile (HANs). Of many chlorinated by-products, chloroform is most prevalent compound formed by the reaction of THMs with bromide in water ${ }^{3}$. Non-volatile HAAs are also widespread in water ${ }^{3}$. HAAs are formed from the naturally occurring iodine and bromine in water. Chloramines are formed by the reaction of chlorine with nitrogenous species in the water. These chloramines further react with ammonia or nitrogen containing compounds in water to form hydrazine. The fate of hydrazine is determined by the presence of ammonia or nitrogen species in the water ${ }^{4}$ Chloroform, Dichloroacetic acid and Hydrazine sulphate are classified as Group 2B carcinogen. Epidemiological studies have revealed many health effects of consuming disinfected water containing chlorinated by-products These include bladder cancer, colon-rectum cancer, brain cancer, lung cancer, kidney cancer and spontaneous abortion in pregnant women ${ }^{5}$.

For the determination of chlorinated by-products, solid phase extraction liquid chromatography tandem mass spectrometry ${ }^{6}$, ion chromatography ${ }^{7,8}$ and High performance Liquid chromatography with Ultraviolet detectors(HPLC) are commonly used analytical techniques reported in literature. With the development of the advanced methods, High Performance Liquid Chromatography has appeared as rapid and highly efficient method to detect or determine CBPs in different water samples. The analysis of organic chemicals in water by HPLC is becoming an increasingly significant area. Considering the deteriorating quality of water in developing countries and resulting severe health concerns, this study has designed to determine selected physicochemical parameters and the concentration of CBPs in tap water by method development and validation of HPLC with diode array detector. This novel technique is successfully employed in analytical chemistry as compared to other chromatographic techniques because it has improved selectivity of the detection system and it works efficiently avoiding tedious sample preparation.

Table 1: Chemical formula and structure of selected byproducts

\begin{tabular}{|c|c|}
\hline CBP & Chemical Formula \\
\hline Hydrazine Sulphate & $\mathrm{H}_{6} \mathrm{~N}_{2} \mathrm{O}_{4} \mathrm{~S}$ \\
\hline Chloroform & $\mathrm{CHCl}_{3}$ \\
\hline Dichloroacetic Acid & $\mathrm{C}_{2} \mathrm{H}_{2} \mathrm{Cl}_{2} \mathrm{O}_{2}$ \\
\hline Bromodichloromethane & $\mathrm{CHBrCl}_{2}$ \\
\hline
\end{tabular}

\section{MATERIALS AND METHODS}

Reagents and Materials

Analytical grade chemicals i.e. Ethyl Acetate, Dichloromethane, Sodium Sulphate, Methanol, Sodium dichloride, Acetonitrile, Distilled Water, Hydrazine Sulphate, Chloroform, Dichloroacetic Acid and Bromodichloromethane were purchased from RDH/Fluka. HPLC grade methanol was supplied by Merck, Germany and $0.45 \mu \mathrm{m}$ Magna nylon filters were of osmosis Inc.

Determination of Physical Parameters

Certain physical parameters of water i.e. $\mathrm{pH}$, Turbidity, Total Suspended Solids and Total Dissolved Solids affect the process of chlorination and formation of DBPs. To analyze the effect of these parameters, they were determined in collected samples following the standard procedures of USEPA. pH

To determine the $\mathrm{pH}$ of water samples, the probe of the $\mathrm{pH}$ meter was first rinsed with distilled water for calibration. $20 \mathrm{ml}$ of water sample was filtered and $\mathrm{pH}$ was noted with the $\mathrm{pH}$ meter.

Turbidity

Turbidity of water samples was determined with the instrument named Nephelometer. The instrument was calibrated before taking the reading. Wate sample was taken in the sample tube of Nephelometer and reading for turbidity was noted.

Total Suspended Solids

$20 \mathrm{ml}$ of water sample was filtered through pre-weighted filter paper. The filter paper was oven-dried at $105^{\circ} \mathrm{C}$ for one hour and weighed again. The difference between the weight of filter paper before and after the filtration was noted. This difference represents the amount of total suspended solids in water sample.

Total Dissolved Solids

$20 \mathrm{ml}$ of water sample was taken in pre-weighted china dish. China dish was kept on burner until the complete evaporation of water in it. After evaporation, china dish was weighed again. The difference between the weights represents the amount of total dissolved solids.

Following table enlists the USEPA methods adopted for the determination of physical parameters:

Table 2: Test methods by USEPA for determination of physical parameters.

\begin{tabular}{|c|c|c|}
\hline Sr. No & Physical Parameters & Test Method \\
\hline 1 & $\mathrm{pH}$ & US EPA 150.1 \\
\hline 2 & Turbidity & US EPA 180.1 \\
\hline 3 & Total Suspended Solids (TSS) & US EPA 160.1 \\
\hline 4 & Total Dissolved Solids (TDS) & US EPA 160.2 \\
\hline
\end{tabular}


Determination of Chlorinated By-Products

Apparatus for Analytical Analysis

The HPLC system having Agilene 1260 Quaternary Pump Gradient System with ODS 18 Column was used for study.

Mobile Phases:

A mobile phase was HPLC grade acetonitrile and water in ratio of 30:70 (v $\therefore$ v) respectively. Both of them were filtered through cellulose filters $(0.2 \mu \mathrm{m})$.

All other parameters were optimized for Chlorination byproducts.

\section{HPLC Conditions:}

The run was $45 \mathrm{~min}$, flow rate optimized as $1 \mathrm{ml} / \mathrm{min}$, column temperature was kept at $25^{\circ} \mathrm{C}$, injection volume maintained at $10 \mu \mathrm{L}$ and $\mathrm{UV}$ detection at $245 \mathrm{~nm}$. $\mathrm{pH}$ was adjusted to 4.5 with phosphoric acid. Remaining conditions are mentioned in Table 3.

Sampling and Sample Pretreatment:

Water samples were collected from main water source (tap water) from a low socioeconomic area in a developing country. In study area, water is supplied through city pipe lines after disinfection by chlorination. Water samples were collected in sterilized glass bottles. All water samples were stored in ice box and were transferred to the laboratories for physicochemical and analytical analysis. For analytical analysis, all samples were filtered through $0.45 \mu \mathrm{m}$ cellulose filter, acidified with $\mathrm{HCl}$ to $\mathrm{pH}<2$ and refrigerated at $4{ }^{\circ} \mathrm{C}$ until analysis

\section{Analytical Technique}

\section{Method Development and Quality control}

A gradient rapid and sensitive HPLC-UV method was developed and validated to determine chlorinated byproducts. To achieve method development optimization studies were performed on each HPLC parameter such as solvent ratio, $\mathrm{pH}$, temperature of column, sample and injection volume, flow rate, wavelength and post time etc. For optimization, one parameter was changed at one time while all others were kept constant.

In order to access the precision in method, each sample was analyzed in triplicate to record the variation (if any). Calibration experiments were tested for linearity, accuracy and precision. Limit of detection (3:1) and limit of quantification (10:1) was calculated as signal-noise ratio. Samples and standards were analyzed in HPLC Agilent 1260 Quaternary Gradient System set ate conditions illustrated in Table 3 to obtain chromatogram.
Table 3: Chromatographic conditions for HPLC Analysis

\begin{tabular}{|c|c|c|}
\hline Sr. No. & Parameters & Specifications \\
\hline 1 & Column & $\begin{array}{c}\text { Zorbax-Eclipse Plus C } 18,4.6 \times \\
1000 \mathrm{~mm}, 3,5, \text { microns }\end{array}$ \\
\hline 2 & Column Temperature & $25^{\circ} \mathrm{C}$ \\
\hline 3 & Flow Rate & $1.0 \mathrm{ml} / \mathrm{min}$ \\
\hline 4 & Mobile Phase & $\begin{array}{c}\text { Water: Acetonitrile } \\
70: 30(\mathrm{v}: \mathrm{v})\end{array}$ \\
\hline 5 & Iso-Gratic & $\begin{array}{c}\text { Water: Acetonitrile } \\
70: 30(\mathrm{v}: \mathrm{v})\end{array}$ \\
\hline 6 & Post Time & $10-20$ min \\
\hline 7 & Detector & DAD Diode \\
\hline 8 & Maximum Wavelength & $245 \mathrm{~nm}$ \\
\hline 9 & Reference Wavelength & $360 \mathrm{~nm}$ \\
\hline
\end{tabular}

Qualitative Analysis

Qualitative analysis was carried out in order to check the presence of selected chlorination byproducts in water samples. To accomplish this purpose, the peak with maximum height was selected in chlorination byproducts standard chromatogram. For each standard peak, retention factor was noted. Existence of each individual standard in samples was confirmed by comparing the retention time of that selected peak in the standard chromatogram with the samples chromatogram.

Quantitative Analysis

To achieve the amount of detected byproducts in each sample, quantitative analysis using the formula formulated by chromo academy was used.

Response factor $=\quad$ Peak area of standard Standard amount used in $1 \mathrm{ml}$ of solvent

Amount of standard in sample $=\quad$ Peak area (sample peak) Response factor for selected byproduct

\section{RESULTS AND DISCUSSIONS}

Following table shows the $\mathrm{pH}$, turbidity. TSS and TDS of water samples.

Table 4: pH, Turbidity, TSS and TDS of Water Samples.

\begin{tabular}{|c|c|c|c|c|c|}
\hline Sr. No & Water Sample & $\mathrm{pH}$ & Turbidity (NTU) & $\begin{array}{c}\text { Amount of TSS } \\
\mathrm{mg} / \mathrm{L}\end{array}$ & $\begin{array}{c}\text { Amount of TDS } \\
\mathrm{mg} / \mathrm{L}\end{array}$ \\
\hline 1 & $\mathrm{~T} 1$ & 6.19 & 0.04 & 50 & 1300 \\
\hline 2 & $\mathrm{~T} 2$ & 5.76 & 0.51 & 100 & 1800 \\
\hline 3 & $\mathrm{~T} 3$ & 6.65 & 1.01 & 100 & 1400 \\
\hline 4 & $\mathrm{~T} 4$ & 6.13 & 0.01 & 100 & 1200 \\
\hline 5 & T5 & 6.78 & 0.51 & 50 & 1650 \\
\hline 6 & T6 & 8.10 & 0.07 & 50 & 2000 \\
\hline 7 & $\mathrm{~T} 7$ & 7.59 & 0.83 & 100 & 1200 \\
\hline 8 & $\mathrm{~T} 8$ & 7.16 & 0.79 & 50 & 1000 \\
\hline 9 & T9 & 6.85 & 0.19 & 50 & 1200 \\
\hline 10 & $\mathrm{~T} 10$ & 7.04 & 0.13 & 50 & 1950 \\
\hline
\end{tabular}

Comparison of Parameters with Standards 


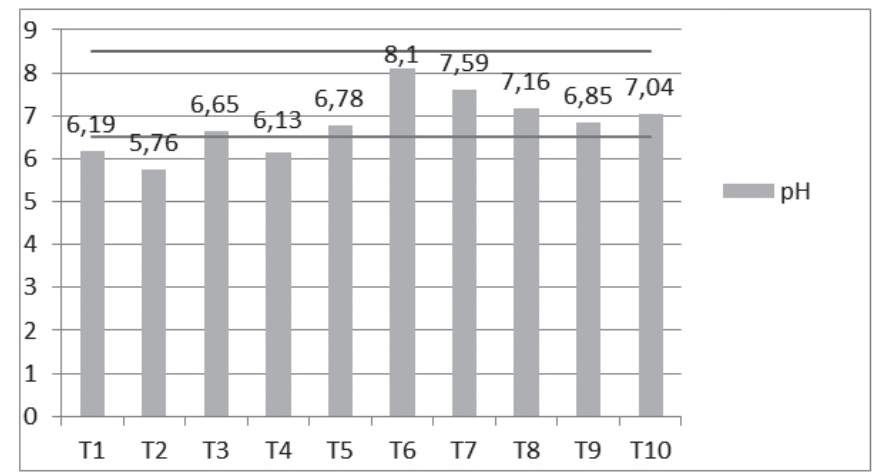

Figure 1: Comparison of $\mathrm{pH}$ with WHO standard.

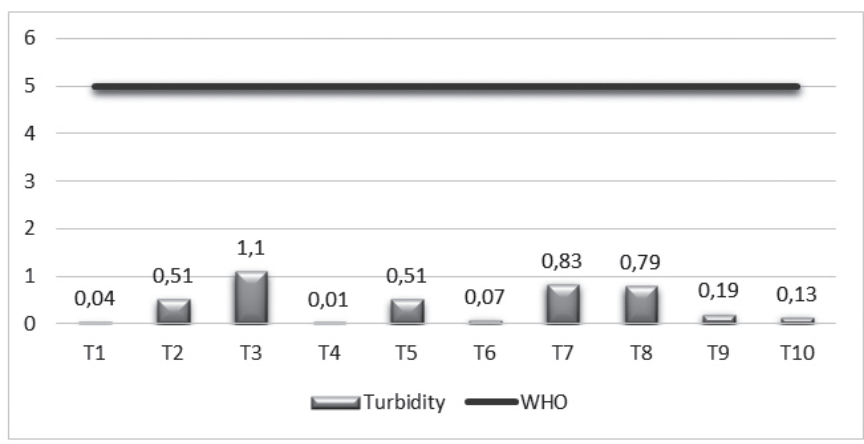

Figure 2: Comparison of turbidity with WHO standard.

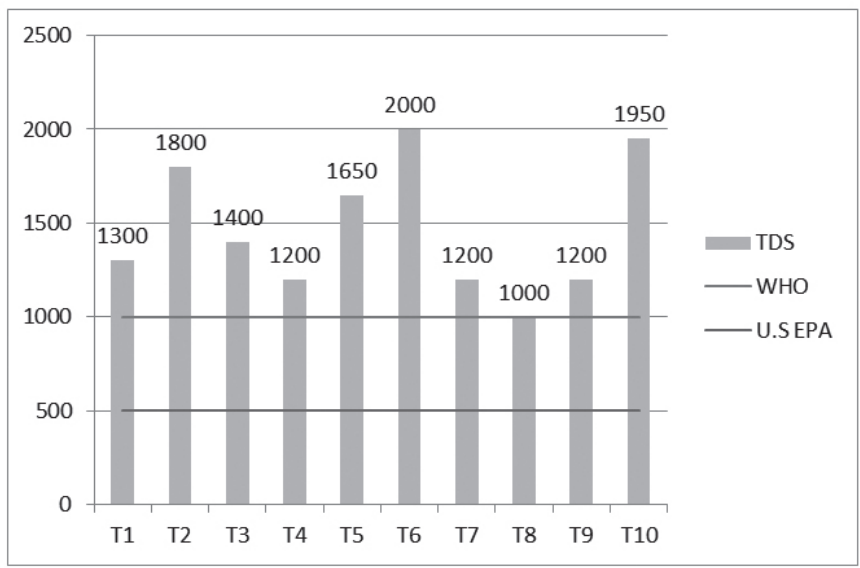

Figure 3: Comparison of TDS with WHO and USEPA.

WHO has recommended $\mathrm{pH}$ of less than 8 for the effective chlorination. Table 4 shows the $\mathrm{pH}$ of all the water samples. $\mathrm{pH}$ of all samples is between the recommended range of WHO and Drinking Water Quality Standards for Pakistan that is $6.5-8.5$ as shown in fig 1 . Table 4 also shows the turbidity unit of each sample. Turbidity of all the samples falls in the recommended range of WHO and DWQS that is less than 5 NTU as shown in fig 2. Also turbidity is within the recommended range of WHO for effective chlorination that is less than 1 NTU. Table 4 shows the amount of total suspended solids in each sample. WHO does not regulate amount of TSS in drinking water. TSS hinders the pathogen killing mechanism of chlorine and enhances the chances of formation of DBPs. Presence of TSS in water samples indicate that efficiency of chlorine is being compromised and there is an increased likelihood of formation of DBPs. Table 4shows the amount of Total Dissolved Solids in water samples. Amount of TDS in water samples are exceeding the recommended levels by WHO and DWQS as shown in the fig 3. The elevated levels of TDS in water samples indicate the presence of natural organic matter which act as a precursor to the formation of chlorination byproducts.
In the research, HPLC analysis was conducted to determine the concentration of chlorinated by-products in various tap water samples. Chlorination disinfection of tap water is considered to be the main reason of presence of chlorinated by-products compounds in tap and water. The HPLC results showed Hydrazine sulfate, Dichloroacetic acid and Chloroform were detected in four tap water samples but Bromodichloromethane was absent in all the samples. Table 5 shows the calculated concentration of chlorinated byproducts in all samples.

Table 5: Concentration of Chlorinated by-products in samples.

\begin{tabular}{|c|c|c|c|c|}
\hline Sample & $\begin{array}{c}\text { Hydrazine } \\
\text { sulfate } \\
\text { (mg/l) }\end{array}$ & $\begin{array}{c}\text { Chloroform } \\
\text { (mg/l) }\end{array}$ & $\begin{array}{c}\text { Dichloroacetic } \\
\text { acid } \\
\text { (mg/l) }\end{array}$ & $\begin{array}{c}\text { Bromodi- } \\
\text { chloromethane } \\
\text { (mg/l) }\end{array}$ \\
\hline T1 & ND & ND & ND & ND \\
\hline T2 & ND & ND & ND & ND \\
\hline T3 & ND & ND & ND & ND \\
\hline T4 & 0.294 & 0.00065090 & 0.0053750 & ND \\
\hline T5 & ND & ND & ND & ND \\
\hline T6 & ND & ND & ND & ND \\
\hline T7 & 13.00 & 0.028746 & 0.23741 & ND \\
\hline T8 & ND & ND & ND & ND \\
\hline T9 & 0.107 & 0.0002250 & 0.0018650 & ND \\
\hline T10 & 1.532 & 0.0033870 & 0.027970 & ND \\
\hline
\end{tabular}

*T= Tap water sample

$* \mathrm{ND}=$ Not Detected

Chloroform belongs to the group of disinfection byproducts named as Trihalomethanes. Chloroform is also recognized as Group 2B Carcinogen by USEPA and IARC. Table 5 shows the amount of Chloroform in samples. In sample T4, $0.00065090 \mathrm{mg} / \mathrm{L}$ Chloroform was found. $0.028746 \mathrm{mg} / \mathrm{L}$, $0.0002250 \mathrm{mg} / \mathrm{L}$ and $0.0033870 \mathrm{mg} / \mathrm{L}$ of Chloroform was found in T7, T9 and T10 respectively. Several studies have reported the carcinogenic effects of chloroform if taken for long period of time. Chloroform is believed to cause liver and kidney cancer as well as damage on central nervous system ${ }^{10}$. A number of epidemiological studies have reported the association of waterborne chloroform with low birth weight and growth retardation of fetuses ${ }^{11}$. Maximum Contamination Level for Chloroform set by Drinking Water Standards and Health Advisories USEPA is $0.06 \mathrm{mg} / \mathrm{L}$ furthermore, the recommended level of Chloroform in drinking water set by WHO is $0.2 \mathrm{mg} / \mathrm{L}$. Figure 4 shows that all the samples contain chloroform below the recommended levels by WHO.

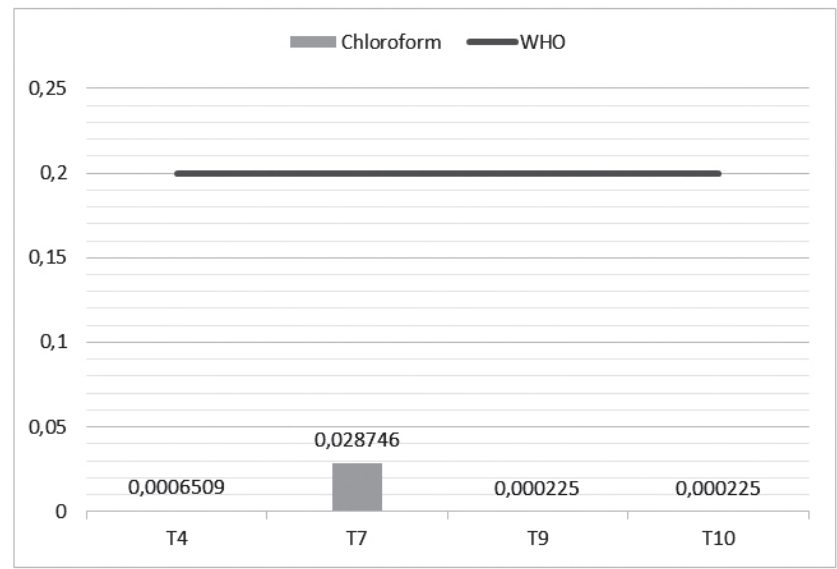

Figure 4: Comparison of Chloroform with WHO.

Dichloroacetic Acid belongs to the group of disinfection byproducts named as Haloacetic Acids. The route of formation of HAAs is similar to the rest of the disinfection byproducts i.e. reaction of chlorine with NOM. HAAs are highly acidic and hydrophilic. USEPA has classified Dichloroacetic 
acid as Group 2B Carcinogen. Several studies have shown the association of HAAs with liver and kidney tumors and effects on developmental functions on animals ${ }^{2}$. Clear evidence of the carcinogenic effect of HAAs on humans is absent so far but they are believed to be mutagenic and carcinogenic if taken for a prolong time above the recommended level. In sample T4, 0.0053750 $\mathrm{mg} / \mathrm{L}$ of Dichloroacetic acid was found. $0.23741 \mathrm{mg} / \mathrm{L}, 0.0018650 \mathrm{mg} / \mathrm{L}$ and 0.027970 of Dichloroacetic acid was found in T7, T9 and T10 respectively. Maximum Contaminant Level for Dichloroacetic acid set by Drinking Water Standards and Health Advisories USEPA is $0.06 \mathrm{mg} / \mathrm{L}$ and $0.05 \mathrm{mg} / \mathrm{L}$ is the recommended amount set by WHO. Figure 5 shows that all samples contain Dichloroacetic acid within the recommended levels except for sample T7 which showed high concentrations of DCAA. The concentration is above the MCL and even above the MCL for total HAAs concentration in water i.e. $0.06 \mathrm{mg} / \mathrm{L}$. The high level of Dichloroacetic acid in drinking water indicates the presence of natural organic matter (NOM) in water and the poor management of chlorine dosing and improper removal of organic matter prior to chlorination.

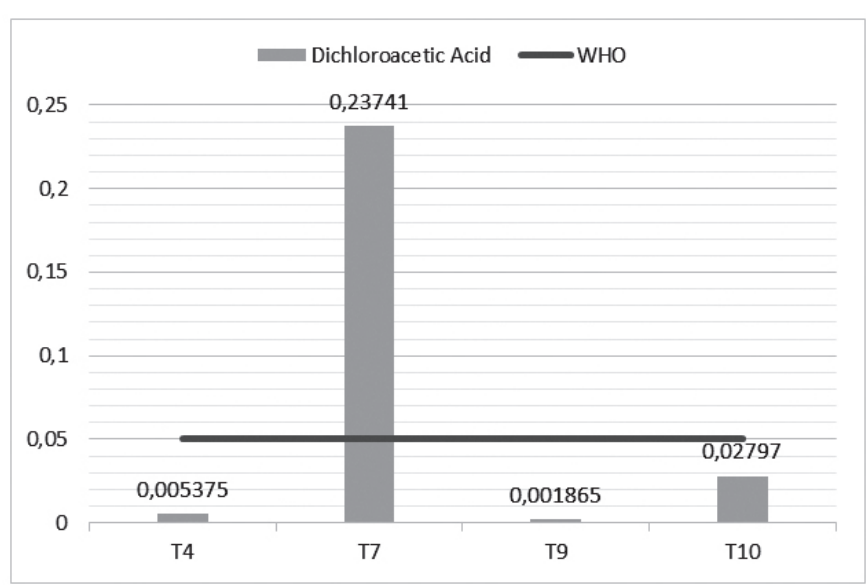

Figure 5: Comparison of Dichloroacetic acid with WHO.

Hydrazine Sulphate is found to cause damage to liver, kidney and Central Nervous System in humans. The United States Environmental Protection Agency (USEPA) has not reported Hydrazine as drinking water contaminant but International Agency for Research in Cancer has classified Hydrazine as Group 2B Carcinogen. European Commission has also regarded Hydrazine as Category 2 for Carcinogenicity. USEPA has also classified Hydrazine as possible human carcinogen having a cancer risk level of $10^{-6} \mathrm{mg} / \mathrm{m}^{3}$ with drinking water concentration of $0.00001 \mathrm{mg} / \mathrm{L}^{12}$. In sample T4, $0.294 \mathrm{mg} / \mathrm{l}$ of Hydrazine Sulphate was found. $13 \mathrm{mg} / \mathrm{l}, 0.107 \mathrm{mg} / \mathrm{l}$ and $1.532 \mathrm{mg} / \mathrm{l}$ of Hydrazine Sulphate was found in T7, T9 and T10 respectively. All samples showed significantly elevated levels of Hydrazine Sulphate. Chlorine reacts with ammonia in the water to form chloramines and these chloramines further react with ammonia to form hydrazine. The presence of free ammonia in the water act as a precursor to the formation of Hydrazine Sulphate and indicate the poor control of chlorine dosing ${ }^{4}$. The excessively high amount of Hydrazine Sulphate in samples show that Water and Sanitation Authority is not regularly monitoring the amount of free ammonia and other NOM in water resulting in the formation of Carcinogenic Hydrazine in drinking water compromising with the health and safety of the consumers.

\section{CONCLUSION}

A method for stimulus determination of chlorinated byproducts was developed using HPLC-UV detector. This method was successfully used to quantify chlorinated byproducts in water. The proposed method is relatively easy and cheap for quantification of important pollutants since derivatization is not required and it includes less use of solvents and other chemicals. Contamination of drinking water results in waterborne diseases which is the leading cause of infant mortality and morbidity in developing countries. To combat this problem, chlorination is widely used technique in developing and under-developed countries because of its easy availability and cost effectiveness and high efficiency in removing pathogens. Unfortunately, chlorine is found to react with natural organic matter present in water and form a class of carcinogens known as disinfection byproducts. This research work was carried out to check the presence of chlorination byproducts i.e. Hydrazine
Sulphate, Chloroform, Dichloroacetic acid and Bromodichloromethane in tap water as well as to quantify their amount. Bromodichloromethane was not detected in any sample. Quantification analysis showed significantly high concentrations of Hydrazine Sulphate in all water samples. Dichloroacetic acid was found to be in high concentrations in sample T7. Chloroform was present within recommended range by WHO and USEPA. Presence of these compounds at such elevated rates are distressing as per the fact that various researches have proved the carcinogenicity of the chlorination byproducts and these compounds are classified as Group 2B carcinogen by IARC. In order to protect human health and ensure the safe availability of water, other types of disinfectants with less ability to form CBPs should be employed.

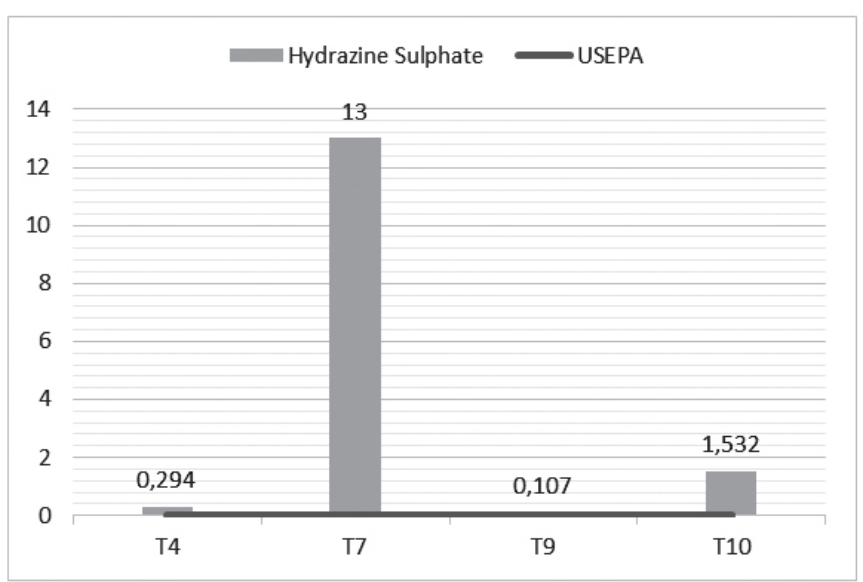

Figure 6: Comparison of Hydrazine Sulphate with USEPA.

\section{Recommendations}

- Water quality should be regularly monitored i.e. $\mathrm{pH}$, Total Suspended Solids, Total Dissolved Solids which act as precursors to the formation of DBPs should be regularly monitored prior to chlorination.

- The concentration of Natural Organic Matter in water should be monitored prior to chlorination and must remove for effective disinfection.

- $\quad$ Chlorine dose should be monitored in order to maintain residual chlorine in water. High dosage of chlorine often leads to the formation of DBPs, so calculated amount of chlorine dose must be added in the water.

- Use of alternate disinfectants having less potential of forming DBPs should be made feasible such as Ultraviolet, Ozonation etc.

\section{ACKNOWLEDGMENT}

Authors would like to thanks Higher Education Commission, Pakistan for funding and Head, Department of Environmental Sciences, Ms Almas Hamid for her help throughout this project.

\section{REFERENCES}

1. C. H. Hsu,W. L. Jeng, R. M. Chang, L. C. Chien, \& B. C. Han, Environmental Research Section A, 85, 77-82, (2001).

2. R. J. Bull, F.C. Kopfler. Health Effects of Disinfectants and Disinfection Byproducts, AWWA, (1991)

3. S. W. Krasner, M. J. McGuire, J. G. Jacaugelo, J. of AWWA, 81, 41-53, (1989)

4. G. Yagila, M. Anbar. J. Am. Chem, 84 (10), 1797-1803, (1962)

5. M. J. Nieuwenhuijsen, M. B. Toledano, N. E. Eaton, J. Fawell, P. Elliott, Occup Environ Med, 75, 73-85, (2000).

6. C. Y. Chen, T. Y. Wen, G. S. Wang,H. W. Cheng, Y. H. Lin, \& G. W. Sci of the Total Environ, 378(3), 352-36, (2007).

7. J. D. Pfaff, \& C. A. Brockhoff, Journal (AWWA), 192-195, (1990).

8. S. D. Richardson, \& C. Postigo. : Springer. Emerging Organic Contaminants and Human Health (pp. 93-137).

9. W. J. Huang, G. C. Fang, \& C. C. Wang. Science of the Total Environment, $345(1), 261-272,(2005)$.

10. R. G. Tardiff, AWWA, 69(12), (1977).

11. D. M. Kramer, F. C. Lynch, P. Isacson, J. W. Hanson., Journal of Epidemiology, 3(5), (1992).

12. L. W. Chang, F.B. Daniel, A.B. DeAngelo. Environ Mol Mutagen, 20(4), 277-288, (1992) 